\title{
Erratum to: The impact of prior long-term versus short-term statin use on the mortality of bacteraemic patients
}

\author{
W. Nseir · J. Mograbi • O. Abu-Elheja • \\ J. Bishara $\cdot$ N. Assy
}

Published online: 15 October 2011

(C) Springer-Verlag 2011

\section{Erratum to: Infection}

\section{DOI 10.1007/s15010-011-0190-9}

In the original published article, unfortunately the authorship was not given correct.

The author names should read as given above.

The online version of the original article can be found under doi:10.1007/s15010-011-0190-9.

W. Nseir $(\bowtie) \cdot$ J. Mograbi Department of Internal Medicine, Unit of Infectious Diseases, Holy Family Hospital, P.O. Box 8, 16100 Nazareth, Israel e-mail:w.nseir@yahoo.com

O. Abu-Elheja

Department of Internal Medicine, Holy Family Hospital,

Nazareth, Israel

J. Bishara

Unit of Infectious Diseases, Rabin Medical Center,

Bellinson Hospital, Petach Tikva, Israel

\section{J. Bishara}

Sackler Faculty of Medicine, Tel-Aviv University,

Tel Aviv, Israel

N. Assy

Liver Unit, Ziv Medical Center, Safed, Israel

N. Assy

Faculty of Medicine, Technion-Israel Institute of Technology,

Haifa, Israel 